\title{
O poder de fazer história divulgando ciência
}

\author{
The power to make history by disseminating science
}

Maria Cecília de Souza Minayo (https://orcid.org/0000-0001-6187-9301) ${ }^{1}$

${ }^{1}$ Departamento de Estudos sobre Violência e Saúde Jorge Careli, Escola Nacional de Saúde Pública Sergio Arouca, Fiocruz. Av. Brasil 4036/700, Manguinhos. 21040-361 Rio de Janeiro RJ Brasil.

maminayo@terra.com.br

\begin{abstract}
This text tells the story of the launching, development, and current status of the scientific Journal Ciência \& Saúde Coletiva from the perspective of who was responsible for its creation, and aims to contribute to the construction of the memory of a national journal, its possibilities, and limitations. While it is a personal statement, the theoretical perspective of narrative is employed in its elaboration, which consists of the use of a singular sequence of events, mental states, events involving human beings as characters or authors, which can be real or imaginary without losing its power as history. Authors who work with studies of narratives and scientific construction processes are reference, and the context in which the story takes place is explained. The study shows the importance of having clear goals, persistent work, and interconnection of important social actors, institutional support, and national and international cooperation in the Journal's management. The role of individuals and organizations is highlighted. The paper concludes that the Journal endorses intellectual production, ensures intellectual property, legitimizes new themes, and defines the limits of what is publishable in Collective $\mathrm{He}$ alth, in line with its primary principles.

Key words Science and technology, Scientific publication, Scientific dissemination, Qualitative approach
\end{abstract}

Resumo Neste texto conta-se a história da criação, do desenvolvimento e do status atual da Revista Ciência \& Saúde Coletiva sob a perspectiva de quem foi responsável pela sua criação. O objetivo é contribuir para a construção da memória de um periódico nacional, suas possibilidades e $l i-$ mitações. Embora seja um depoimento pessoal, na sua elaboração se utiliza a perspectiva teórica da narrativa, que consiste na utilização de uma sequência singular de eventos, estados mentais, ocorrências envolvendo seres humanos como personagens ou autores, podendo ser real ou imaginária sem perder seu poder como história. Autores que trabalham com estudos de narrativas e processos de construção científica são referenciados; assim como é explicitado o contexto em que a história acontece. O estudo mostra a importância de, na gestão da Revista, ter metas claras, persistência no trabalho e contar com a interconexão de importantes atores sociais, de apoios institucionais e de cooperação nacional e internacional. O papel dos indivíduos e das organizações é realçado. O artigo conclui que a Revista avaliza a produção intelectual, assegura a propriedade intelectual, legitima novos temas e define os limites do que é publicável no campo da saúde coletiva, sendo fiel a seus princípios originais.

Palavras-chave Ciência e tecnologia, Publicação científica, Divulgação científica, Abordagem qualitativa 


\section{Introdução}

Este artigo tem o objetivo de oferecer uma narrativa pessoal sobre a trajetória da Revista Ciência \& Saúde Coletiva (C\&SC). Eu a escrevo na primeira pessoa porque participo dessa saga desde o seu nascimento até o momento presente: junto com a Revista, comemoro 25 anos como EditoraChefe.

Segundo Bruner ${ }^{1}$, a narrativa é composta pela sequência singular de eventos, estados mentais, ocorrências envolvendo seres humanos como personagens ou autores, podendo ser real ou imaginária sem perder seu poder como história. $\mathrm{O}$ autor observa "nós viemos inicialmente equipados se não com uma "teoria" da mente, certamente, com um conjunto de predisposições para interpretar o mundo social de uma forma particular e para agir sobre as nossas interpreta-

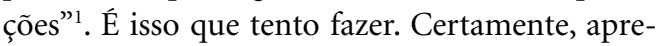
sento uma visão parcial e incompleta dos fatos, uma vez que, como assevera Gadamer ${ }^{2}$, o narrador representa a totalidade, mas não a contém, pois, a história é feita de muitas mãos e pode ser interpretada de forma polissêmica.

Inicio falando do que chamo mito de origem e seu contexto, em seguida faço uma leitura seguindo o conceito de tempo estrutural, definido por Evans Pritchard ${ }^{3}$, como o tempo dos fatos mais relevantes e significativos para o narrador, independente de sua cronologia, pois nele se misturam razão e emoção; e termino com algumas considerações em forma de síntese.

\section{O Mito de origem}

$\mathrm{Na}$ antropologia, esta expressão "mito de origem" diz respeito àquela história ao mesmo tempo real e imaginária, pessoal ou coletiva, que marca um povo, uma instituição ou um acontecimento $^{4}$. Nesse sentido, sou eu que penso a mim mesma na construção da C\&SC, junto com cada uma das pessoas que a edificam e a sustentam, no que ela porta de seu berço e nicho que é a Associação Brasileira de Saúde Coletiva (Abrasco), no que ela tem de comum com todas as outras revistas da área, e na sua inserção e evolução no mundo da comunicação e da divulgação científica. Minha hipótese é que, reafirmando suas evidentes interconexões, C\&SC apresenta uma personalidade própria e não teria razão de existir se dissolvesse sua especificidade.

C\&SC se iniciou quando a Abrasco - cuja razão social era ainda "Associação Brasileira de Pós-Graduação em Saúde Coletiva” - completava
15 anos de existência. Sua criação ocorreu num momento de amadurecimento e consolidação de um forte movimento social para construção (ainda inconclusa) de um sistema universal de saúde no país ${ }^{5}$. Precederam seu nascimento vários documentos, textos e livros com o selo da Abrasco, em cujo seio, duas comissões importantes e estruturantes estavam em pleno florescimento: a de Epidemiologia e a de Ciências Sociais e Saúde, além de diversos grupos de trabalho. Vários Congressos gerais (carinhosamente denominados Abrascões) assim como diversos setoriais de Epidemiologia e um primeiro de Ciências Sociais e Saúde já haviam acontecido.

Ainda que fossem evidentes os êxitos da Associação na produção de um novo conhecimento no campo da saúde, nos primeiros anos da década de 1990 pairavam muitas críticas sobre a cientificidade da área chamada "saúde coletiva", tida como uma comunidade de conhecimento muito mais política e politizada do que de expressão acadêmica. Tais críticas, institucionalmente, se expressavam nos comitês de medicina da Coordenação de Aperfeiçoamento de Pessoal de Nível Superior (CAPES) e do Conselho Nacional de Desenvolvimento Científico e Tecnológico (CNPq), cuja grande influência interferia na avaliação tanto dos cursos de pós-graduação como no julgamento da produção dos pesquisadores. Foi nessa conjuntura que, por iniciativa da diretoria da Abrasco, primeiro se conduziu um processo avaliativo do conjunto das pós-graduações da área, em cuja atividade renomados pesquisadores se engajaram. A partir desse movimento, várias outras decisões foram tomadas, entre elas, a criação de uma Revista que representasse o conceito de "Saúde Coletiva".

Falo primeiro da avaliação, realizada entre 1994 e 1996, como uma pesquisa nacional sobre as condições, o desempenho e os desafios das Pós-Graduações em Saúde Coletiva/Saúde Públi$\mathrm{ca} /$ Medicina Preventiva, com apoio institucional e financeiro do CNPq e da CAPES. Essa atividade se encerrou com um seminário do qual participaram, além dos coordenadores dos cursos, autores e coordenadores da pesquisa, as principais lideranças da área, dois consultores internacionais e representantes das instituições de fomento e da Organização Pan-americana de Saúde (OPAS).

Por ter sido um evento de afirmação acadêmica da área, é importante ressaltar quatro de suas conclusões teóricas e pragmáticas: (1) em primeiro lugar, os currículos dos cursos, as atividades dos estudantes e a produção científica dos docentes e pesquisadores evidenciaram as mes- 
mas qualidades e defeitos atribuídos às pós-graduações de outros campos do conhecimento nos relatórios da CAPES; (2) o estudo mostrou uma comunidade acadêmica produtiva, em pleno processo de amadurecimento, em torno do conceito "Saúde Coletiva", conceito nascido do movimento sanitário e sustentado em três pilares: geração de conhecimento, ação prática a favor e com participação da sociedade e atuação no campo político do setor; (3) para dar continuidade à reflexão coletiva e enfrentar os desafios apontados, foi criado o Fórum dos Coordenadores de Pós-graduação que perdura até hoje; (4) já nesse momento foi decidida a criação de uma revista científica, cogitada havia algum tempo. Toda essa história e os resultados da avaliação estão registrados nas primeiras edições da C\&SC ${ }^{6-12}$.

Fui a primeira mulher presidente da Abrasco, coordenei a referida pesquisa nacional e também a criação do Fórum de Coordenadores. Numa das últimas reuniões de meu mandato, após encerramento do processo avaliativo, a Diretoria unanimemente bateu o martelo sobre a criação de uma Revista Científica (aventada anteriormente) que representasse a riqueza e a diversidade da área. Embora o periódico devesse, corretamente, focalizar o pilar que sustenta qualquer empreendimento acadêmico, "a ciência", seria sua missão precípua, evidenciar em seu conteúdo, os três lados do triângulo, qualificando a saúde como um bem coletivo e universal, a sociedade como parte de sua ação e participação e as políticas do setor como objeto de aperfeiçoamento e crítica. Foime dada, nessa reunião, a incumbência de liderar essa criação que agora completa 25 anos.

Já no $2^{\circ}$ semestre de 1996, publicamos a primeira edição da que foi denominada, por consenso, Ciência \& Saúde Coletiva com o escopo de ser um espaço científico para discussões, debates, apresentação de pesquisas, exposição de novas ideias e de controvérsias sobre a área. Selava-se o casamento dos dois termos, numa história que não parou mais. Seus três primeiros números são o testemunho do esforço inicial de atrair autores e construir um trabalho acadêmico de respeito. O Conselho Científico foi entregue a renomados pesquisadores das subáreas principais que compõem o campo da saúde coletiva; o Conselho Editorial incluiu, desde sempre, docentes e pesquisadores das pós-graduações das diversas regiões do país. Para sua sustentação financeira, ficou estabelecido que se aumentasse a anuidade da Abrasco em 10\%.

A C\&SC nasceu pequena, artesanal e esteticamente pouco elaborada, porém seu conteúdo, impressionantemente, desde a origem, reflete força e compromisso com a missão que lhe foi confiada. Hoje, ao reler as primeiras edições, foi impossível não me emocionar recordando companheiros como Eleutério Rodrigues Neto que já não está entre nós. Mas também constatar que dos autores inaugurais, a maioria continua ativa. E vários deles, inclusive, contribuem com esta Edição Comemorativa como é o caso de Jairnilson Silva Paim e Everardo Duarte Nunes. Os nomes e o pensamento de todos estão registrados no site da Revista (www.cienciaesaudecoletiva. com.br), e também no site do SciELO (www.scielo.org), onde a coleção inteira do periódico pode ser acessada.

C\&SC começou com apenas duas edições anuais. Em 1998, nós juntos, o Conselho de Editores e os Editores Associados, convencemos a diretoria da Abrasco de que seria preciso investir muito mais em sua forma e conteúdo. Depois dos três primeiros números, foi possível dar-lhe algumas características que acompanham sua história: (1) ser uma revista temática, o que a diferenciaria das já existentes e a tornaria relevante, na medida em que aprofundasse assuntos e problemas de interesse da Saúde Coletiva; (2) abranger todos os segmentos dessa área intrinsecamente multidisciplinar; (3) orientar-se para um tipo de ciência voltada para o desenvolvimento do SUS; e (4) obviamente, ter independência editorial, guiando-se pelo mérito científico e pelas normas internacionais de divulgação científica. Um detalhe estético: a capa da revista foi desenhada para projetar a imagem de pessoas em movimento ideia do coletivo - por meio de uma foto estilizada do povo caminhando pela Avenida Rio Branco no Rio de Janeiro/RJ. Desde a segunda edição do ano 1998, a Revista passou ter essa identidade visual que possui até hoje e a dividir os conteúdos em "temáticos" e "temas livres", além de divulgar outros tipos de documentos (opiniões, entrevistas, resenhas e cartas).

\section{Marcos relevantes do percurso}

Em 2002, a C\&SC conseguiu ser incluída na coleção da Scientific Electronic Library Online (SciELO) e passou a publicar quatro edições por ano. Desse salto nunca retroagiu, sendo reconhecida por sua periodicidade e por seguir normas científicas internacionais. A publicação trimestral foi inaugurada com uma edição que analisa a Pesquisa Nacional de Amostra em Domicílio (PNAD) de Saúde de 1998, depois de, em 2001, haver divulgado uma edição especial em come- 
moração aos 100 anos de Saúde Pública no Brasil. Em pleno processo de crescimento, em 2005, a C\&SC tornou-se bimestral. Marcou essa mudança com um número sobre Trabalho, Saúde e Ambiente, tema que acompanha sua história desde 1998.

O aumento de edições correspondia ao crescimento da demanda. Mas a meta não era apenas quantitativa, pretendíamos investir no reconhecimento internacional da C\&SC, buscando indexá-la no Medline onde estão todas as revistas relevantes da área de medicina e saúde pública do mundo. Depois de duas tentativas, em 2007, o alvo foi atingido. Embora o documento de inclusão na coleção assinalasse que o aceite fosse provisório e probatório, para que a Revista mostrasse periodicidade e adequação a normas internacionais, a decisão nunca retroagiu, ao contrário, corroborou com o aumento de sua legitimidade. Marcando o feito, a primeira edição do ano analisou as teses da $13^{\text {a }}$ Conferência Nacional de Saúde, reafirmando seu compromisso científico com o SUS.

Em 2006, criamos uma página online da Revista onde, além de informações aos colaboradores, editoriais e notícias, passamos a divulgar no prelo, em até 48 horas todos os artigos aprovados. Em 2017, esse site foi totalmente renovado e dinamizado. Assim, além de instruções e normas para os colaboradores, contém integralmente o acervo da C\&SC, os artigos ahead of print, o release da edição mais atual, as chamadas para edições temáticas, notícias atualizadas do campo da saúde coletiva e inserção da Revista nas redes sociais. Tem sido feito um esforço intenso orientado à popularização dos conhecimentos divulgados na Revista, principalmente por meio das redes sociais, com a divulgação de releases de vários artigos de cada edição temática. Tal iniciativa, deu-se com a criação da área Editor de Comunicação e Divulgação, criada em junho de 2017 com a colaboração do Prof. Luiz Felipe Pinto e atualmente contamos com a colaboração voluntária do jornalista Neyson Freire e o generoso apoio do Conselho Federal de Enfermagem (COFEN), a quem agradecemos imensamente.

Em 2008, o número de edições subiu de seis para oito acompanhando o aumento da procura dos autores e a Revista conseguiu ser indexada também na Web of Science, terceiro alvo para seu reconhecimento internacional. Em seguida, logramos a indexação na Scopus e, paulatinamente, incluímos a C\&SC em 22 bases de dados, sendo três nacionais, três regionais e as outras, internacionais. O esforço de expor ao mundo a produção em saúde coletiva só incrementou sua credibilidade. A demanda dos autores cresceu de tal forma que em 2011 aumentamos o número de edições (12/ano) e o número de artigos por edição (30).

A partir de 2018, continuando as 12 edições/ ano, a quantidade de artigos publicados em cada uma passou para 35. Apesar de possuir um processo de avaliação rigoroso que seleciona não mais que $19 \%$ dos originais por ano, um represamento de textos à espera de publicação persiste, o que ocorre pelo aumento enorme da demanda: o sistema de submissão online registra uma média de 3.500 originais. Os artigos aprovados, no entanto, são imediatamente divulgados na página da revista em ahead of print como já mencionado. Há dificuldades reais e concretas para incrementar mais a periodicidade das publicações: a equipe executiva é pequena e faltam recursos financeiros.

Desde 2014, a versão integral dos artigos é divulgada nas diversas bases de dados, com mais de $75 \%$ deles vertidos para o inglês. O objetivo é facilitar a internacionalização da Revista, dos autores e do conhecimento gerado no país. Atualmente Ciência \& Saúde Coletiva está classificada na categoria A3 no sistema Qualis/Capes.

Em resumo, ao completar 25 anos, considero evidente que a C\&SC tem muito que comemorar! Além de estar em acesso aberto em 22 bases de dados nacionais e internacionais e também em sua página web (www.cienciaesaudecoletiva. com.br), ela se encontra presente nas redes sociais: Facebook, Twitter e Instagram. Há quatro anos mantém a posição de liderança, como o periódico brasileiro mais citado de todas as áreas do conhecimento do país no Google Scholar. Em 2019, pela primeira vez, seu fator de impacto na Web of Science atingiu mais de um ponto, chegando a 1.008! Em setembro de 2019, recebeu um prêmio internacional, o Research Excellence Awards Brazil, concedido pelo Web of Science Group, pertencente à Editora Clarivate Analytics. A iniciativa premiou o bom desempenho da pesquisa brasileira e a Revista foi contemplada na categoria "Prêmio SciELO Citation Index"13. Poder-se-ia dizer que tudo isso é pouco para padrões internacionais, mas é importante conquista para uma revista brasileira, quando se compara o cenário nacional dos periódicos.

Todo o avanço da C\&SC constitui-se numa evolução progressiva como descrito. Porém, esse desempenho tem um contexto e um pano de fundo. A crescente produção científica do Brasil na área da saúde está intimamente ligada ao desen- 
volvimento da pós-graduação. Por exemplo, por ocasião do nascimento da Revista estavam em funcionamento 17 cursos de Mestrado e nove de Doutorado em Saúde Coletiva ${ }^{7}$. Ao final de 2018, segundo dados do relatório de área mais recen$\mathrm{te}^{14}$, havia 94 programas em funcionamento, sendo 52 acadêmicos e 42 profissionais. Essa última modalidade surgiu em anos recente e evidencia, além do aumento quantitativo, maior variedade na oferta do ensino. O crescimento da pós-graduação implicou no aumento do número doutores - já que possuir formação nesse nível foi se tornando uma exigência básica para ser docente dos programas - e incremento na formação de alto nível. Por exemplo, no quadriênio 2013-2016 foram concluídas cerca de 4.400 dissertações de mestrado acadêmico ou profissional e 1.200 teses de doutorado ${ }^{14}$. O segundo ponto de contexto são as exigências de produtividade científica vinculadas à aprovação e à competitividade dos cursos, por parte da CAPES, e aos critérios do CNPq para classificar os pesquisadores. Não só os docentes, mas também os mestrandos e doutorandos foram sendo compelidos a publicar e os artigos passaram a ser "um artigo de luxo" e de grande valor na avaliação dos programas e dos currículos. É óbvio que tais movimentos, cada vez mais competitivos, passaram a se refletir no aumento da demanda às Revistas Científicas. Um terceiro aspecto de contexto para o aumento exponencial de originais no sistema de submissão da Ciência \& Saúde Coletiva é o fato dos periódicos mais renomados da área estabelecerem nichos para sua atuação, ou barreiras em relação a certos temas, enquanto que a C\&SC manteve o critério de abrangência do campo, conforme sua proposta original.

Em resumo, a atual configuração da Revista se insere no contexto das transformações acadêmicas brasileiras, ao tempo em que mantém seus princípios de origem. Seu crescimento não é um feito único nem isolado no cenário das publicações científicas nacionais. Porém, não se pode negar que sua elevada produtividade contribui para que o Brasil ocupe o $13^{\circ}$ lugar no universo dos países que apresentam maior volume de publicações científicas.

Um problema vem atravessando a história da C\&SC: o financiamento! Essa questão que compartilho com boa parte dos editores do país, a meu ver, não deveria ser um obstáculo a ocupar a mente e os nervos do editor. E sim, objeto de uma Política Pública de Estado adequada e permanente, pois no mundo contemporâneo, o país que não investe em ciência, tecnologia, inovação e divulgação científica perde o bonde da história e fica mais pobre e dependente do que aqueles que o fazem ${ }^{15-17}$.

\section{Pessoas e instituições referenciais}

Levar o cotidiano e gerenciar as transformações de um periódico como a C\&SC é um trabalho duro e minucioso que só encontra condições de possibilidade se for realizado de forma técnica, solidária e colaborativa. Aqui falo do engajamento e do papel de algumas pessoas e de instituições.

Teoricamente, o papel do indivíduo versus o papel das organizações é um tema clássico que percorre toda a história da sociologia, o que resumo aqui, utilizando a compreensão de Bourdieu $^{18}$ e de Norbert Elias ${ }^{19}$, segundo os quais, há uma interdependência entre indivíduo e sociedade e entre subjetividades e estruturas. O papel dos indivíduos é fundamental, mas precisa ser entendido sempre dentro das condições históricas e sociais em que atuam, considerando redes de relações objetivas e subjetivas e disputas simbólicas.

Pessoas Imprescindíveis - Não há dúvidas de que todos os resultados positivos e os bons augúrios para o futuro da C\&SC, resguardadas as condições históricas e sociais, se devem a uma equipe coesa e comprometida, constituída pelo corpo editorial; o grupo executivo responsável pelo dia a dia do processo de trabalho; os revisores, os avaliadores, os autores e os leitores. É esse time unido e dedicado que fez e faz possível a jornada que completa 25 anos.

Começo referindo-me ao trabalho colaborativo e respeitoso que, junto comigo, exercem Romeu Gomes e Antonio Augusto Moura da Silva, na função de editores-chefes. Romeu junta competência reconhecida na área, com uma sistemática de trabalho produtiva e inquestionável dedicação ao gerenciamento do processo de avaliação por pares. Desde 2009, compartilhamos a chefia da Revista, fazendo muito mais do que cumprir uma divisão de tarefas. Trabalhar com ele é apoiar o corpo cansado num ombro amigo e ter certeza da lealdade e da sinceridade. Em 2018, agregamos à dupla, o colega Antonio Augusto, repartindo com ele a gestão de avaliação dos trabalhos de abordagem estatística e epidemiológica. Gentil, ágil e comprometido, é assim que Romeu e eu vivenciamos a presença desse novo e imprescindível companheiro de jornada. Tornamo-nos uma trindade na chefia da C\&SC, de forma que o compartilhamento do todo e o foco em cada 
parte nos tornam corresponsáveis e nos enriquecem mutuamente. Essa chefia é assessorada por um Conselho de Política Editorial, composta por eminentes cientistas nacionais e internacionais da área, corresponsáveis pela orientação das publicações: Cesar Victora; Eleonor Minho Conill; Everardo D. Nunes; Jairnilson Silva Paim; Jorge Alberto B. Iriart; Hillegonda Maria Dutilh; Moysés Szklo; Nelson da Cruz Gouveia; Zulmira Maria de A. Hartz.

Em seguida, falo dos Editores Associados, um grupo formado por 20 especialistas nos temas mais publicados na C\&SC. Sua tarefa é fundamental para endereçar adequadamente os artigos para pareceristas e endossar sua aprovação. Eles são corresponsáveis com os Editores-chefes pela qualidade dos artigos publicados. É impossível no curto espaço deste artigo tecer um comentário agradecido a cada um em particular. Por isso, mesmo sabendo que seus nomes estão expostos na contracapa da revista impressa e no site, faço questão de citá-los, como uma forma de reverenciá-los. Na pessoa dos que atualmente cumprem esta tarefa, expresso a mais sincera gratidão a todos os que, ao longo do tempo, ocuparam a mesma função tão importante, tão trabalhosa e tão necessária (Quadro 1).

Em terceiro lugar, refiro-me à Equipe Executiva da qual depende colocar uma edição/mês na rua, cumprindo os invisíveis e infinitos pro- cedimentos que o processo editorial requer. $\mathrm{Na}$ pessoa do grupo atual, minha gratidão a Lilian Vicentin que acompanhou o nascimento e os primeiros passos da Revista. Depois dela, acompanhando o aumento da demanda, ampliamos este setor de forma a estabelecer um processo de trabalho com divisão de tarefas, mas colaborativo e solidário: cada um em seu pedaço, mas um por todos e todos por um. Preciso dizer os nomes: Danúzia da Rocha de Paula, bibliotecária e normalizadora, a pessoa mais antiga e fundamental na equipe; Luiza Pimenta Gualhano, assistente editorial e coordenadora de relacionamento com os autores de artigos aprovados, vigilância de plágio e traduções para o inglês; Telma Freitas da S. Pereira, editora executiva responsável pelo planejamento e financiamento da revista e pela coordenação editorial das propostas e das dinâmicas dos números temáticos; Raimunda Matilde do N. Mangas, editora executiva responsável pelo planejamento e coordenação do processo de editoração. Essas profissionais, todas com curso superior e pós-graduações, formadas na prática e em vários cursos de aperfeiçoamento em editoração científica, conduzem suas atividades de forma profissional e coordenada. Infelizmente faltalhes uma compensação financeira merecida: não posso deixar de mencionar. $\mathrm{Na}$ equipe executiva agregam-se colegas igualmente imprescindíveis: Adriana R. Fontes, diagramadora; Marcelo Z.

Quando 1. Editores Associados, respectivas especialidades e área de avaliação - 2020.

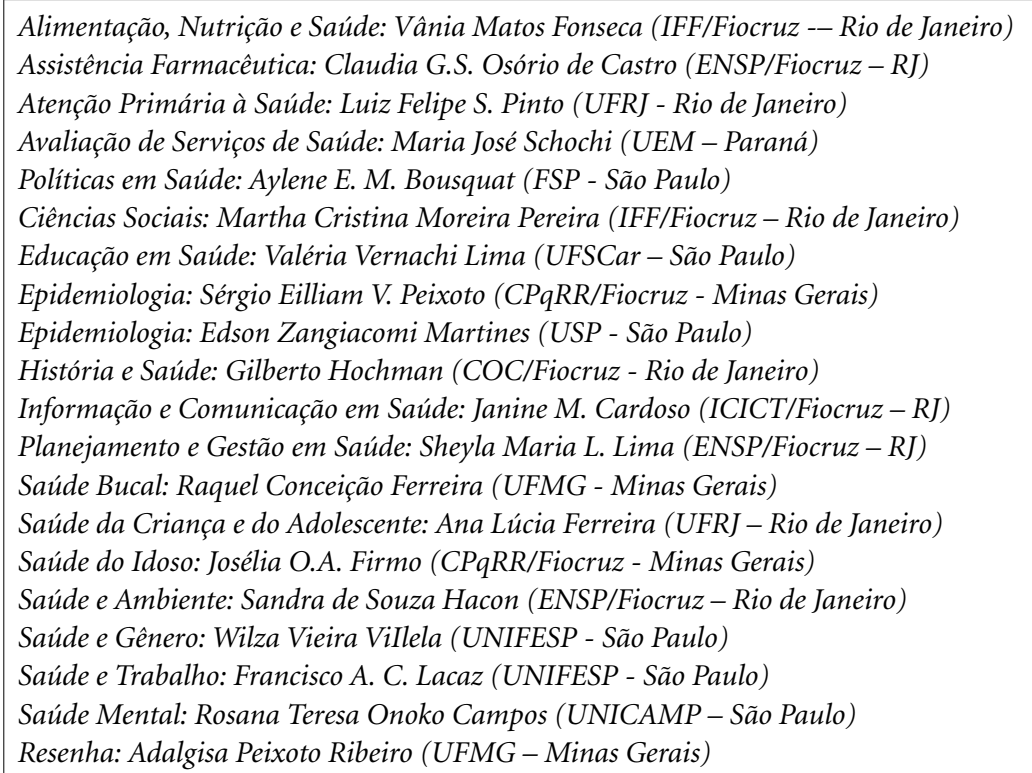


Afonso e Lívia Marinho, revisores de português; Derrick Phillips e Jean-Pierre Barakat, tradutores; Neyson P. Freire, diretor de comunicação e divulgação e a bolsista de iniciação científica Karine M. de Oliveira que atua em colaboração com a editoria executiva. Só tenho palmas para essa plêiade de pessoas, sem as quais a C\&SC não poderia se materializar e ser o que é.

C\&SC tem um Conselho Editorial composto por 73 docentes e pesquisadores com doutorado na área, representando todas as pós-graduações em Saúde Coletiva brasileira, das mais diversas localidades do país. Nesse corpo de apoio da revista há ainda 31 colaboradores internacionais. O principal papel desse imprescindível grupo é contribuir como pareceres, sendo demandados pelos editores associados. Além dos nomes que constam oficialmente do Conselho, temos um acervo de cerca de 1.000 pareceristas ad hoc que colaboram no processo de avaliação, durante um ano. A esse conjunto dedicado e fiel de pesquisadores e docentes, a mais profunda gratidão!

Exemplifico a força do trabalho coletivo, apresentando alguns dados do ano que terminou. Em 2019 foram publicadas 12 edições com 463 artigos, sendo 321 deles escritos em inglês ou traduzidos e 21 elaborados em espanhol. A coleção de 2019 traz a presença de 1.666 autores brasileiros e 182 estrangeiros.

Instituições Fundamentais - A Revista é obra e criatura da Abrasco e, nesse sentido, acompanha, dentre outros movimentos, o crescimento da instituição. Apesar de ser propriedade da Associação, não é, no entanto, um veículo institucional. Mesmo respeitando as várias diretorias, ela tem um corpo de vigilância epistemológica independente que obedece à organização e à avaliação por pares, o que filósofos da ciência como Popper $^{20}$ consideram condição essencial para validação do conhecimento. É importante assinalar essa característica, porque, vez por outra, os editores-chefes se deparam com algumas ideias intervencionistas, incabíveis num periódico científico. A meu ver, a independência acadêmica contribui para a legitimidade e o prestígio da Abrasco e da área de saúde coletiva, que por sua vez legitimam a Revista, como assinalam Minayo e Gomes ${ }^{21}$ :

De um lado, [ela] contribui com o rigor das avaliações para que cresça a massa crítica da área e assim vai delimitando - ainda que de forma bastante generosa - suas fronteiras de conhecimento. De outro, num processo recursivo, traz para a Associação o reconhecimento nacional e internacional, ao mesmo tempo em que mantém o compromisso inegociável com o SUS ${ }^{21}$.
Fundação Oswaldo Cruz - No Brasil, a experiência mostra que a existência e a subsistência de uma Revista Científica dependem do apoio de instituições, pois inexiste uma política de Estado que proteja os veículos nacionais de comunicação científica. No caso da Revista Ciência \& Saúde Coletiva o suporte é duplamente dividido. A Abrasco mantém um corpo técnico e executivo mínimo. E a parceria com a Fiocruz permite que partes do processo editorial se sustentem. É o caso da revisão técnica, da diagramação, de tradução dos editoriais e resumos para o inglês, da cessão do espaço de funcionamento da Revista e, até o momento, do pagamento da impressão. Considero muito importante tornar público este patrocínio porque, infelizmente, aqueles $10 \%$ das anuidades, estabelecidos no nascimento da Revista para mantê-la, acabaram por não ter essa aplicação e nem seriam suficientes. Devo mencionar que no decorrer de sua trajetória, houve pelo menos dois momentos de apagão financeiro em que a ordem da Abrasco era parar de publicar. O leitor pode imaginar como foram apavorantes tais situações: atender à ordem seria aceitar dar fim a um processo lento e progressivo de legitimação e ferir de morte o compromisso de periodicidade com os autores e os leitores.

Nos dois momentos, foi a Presidência da Fiocruz que protegeu a C\&SC. Por isso, tenho certeza de que, sejam quais forem os que estiverem à frente da revista terão seu apoio, fruto da consciência de responsabilidade institucional frente à área de Saúde Coletiva e ao SUS. À Fiocruz, o imenso agradecimento da C\&SC que, na pessoa de Paulo Gadelha e Nísia Trindade Lima, reverencia a Instituição.

Instituições de fomento: CNPQ, CAPES, FAPERJ-Dentre todas, a que mais tem contribuído para manutenção da C\&SC é o CNPQ, que, em alguns momentos, o fez de forma articulada com a CAPES. Sobre esse tipo de apoio, faço algumas ponderações: eu o considero fundamental, pois é precedido por avaliação de mérito, o que legitima a Revista. No entanto, ele nunca foi suficiente para manter nem duas edições; ao longo do tempo, a quantia destinada à Revista (lembrando que publicamos 12 números/ano) em lugar de aumentar, vem diminuindo progressivamente. A mesma escassez de financiamento ocorre hoje com o conjunto dos periódicos nacionais. Recursos de várias outras instituições como o Ministério da Saúde, Organização Pan-americana de Saúde, Fundações de Apoio ou provenientes de projetos de pesquisa têm contribuído para a divulgação de Edições Temáticas. 
A insegurança financeira tem levado muitas Revistas a cobrarem para publicar. Não faço juízo de valor sobre o assunto, mas repito que não podemos nos calar frente à ausência de uma política de Estado para prestigiar os Periódicos Nacionais, tal como ocorre em outros países, a exemplo da China. A meu ver há uma mentalidade de colonizado que impregna as decisões sobre o assunto, como identificado também por Beigel $^{22}$, segundo o qual, o próprio delineamento dos sistemas de avaliação ao redor do mundo, dos quais dependem o financiamento da pesquisa e o desempenho do pesquisador, excluem o conhecimento gerado nos circuitos periféricos ao reforçar a pressão por publicação em periódicos mainstream.

SciELO - Criado em 1998, o SciELO é um bem da sociedade científica brasileira, mantido e financiado pela FAPESP, com pequena contribuição do CNPq e da CAPES. Às vezes tratado como rede, programa ou plataforma, o SciELO caracteriza a dinâmica contemporânea da comunicação científica, com ênfase na consolidação do acesso aberto, na ampliação das metodologias e métricas de avaliação dos periódicos, nos produtos e serviços de editoração e publicação científica e no papel crítico que têm as políticas e programas públicos de apoio e avaliação da pesquisa comunicada pelos periódicos. A C\&SC entrou nesse sistema em 2002, e desde então é beneficiária de sua filosofia e de sua ação e se sente muito agradecida por ser parte dele. Na pessoa de Abel Packer, indutor de boas práticas e de mudanças, $o$ mais profundo reconhecimento.

\section{Considerações finais}

Ao encerrar este texto, espero ter cumprido o objetivo de contar alguns aspectos significativos da trajetória de um periódico pelo olhar de quem teve a honra de criá-lo, com o apoio de uma multidão de pessoas que acompanharam seus passos, envolveram-se em seu desenvolvimento, avalizaram sua caminhada e comemoram seus 25 anos. Embora tenha descrito fatos objetivos que legitimaram a existência da C\&SC, considero e peço ao leitor que considere, também, que esta é uma história contada na primeira pessoa. Portanto, a narrativa contém uma sequência de eventos que entraram para a biografia de quem narra e deve ser entendida como uma experiência que junta razão e emoção ${ }^{23}$. Assim sendo, ela se torna um fato social ${ }^{24}$ ou uma ação social ${ }^{25}$ e testifica que objetividade e subjetividade estão presentes, de forma intrínseca, em qualquer criação humana.

Usei a expressão "mito de origem" e escrevi mais extensamente sobre as circunstâncias e as condições de possibilidade de criação da C\&SC, pedindo "uma licença acadêmica" ao pensamento de Lévi-Strauss", segundo o qual, as sociedades [as organizações] se pensam e viajam entre si e, ao mesmo tempo, pensam a si mesmas, com a ressalva de que jamais pertencem a si próprias, pois ao viajar elas se transformam. Busquei mostrar essa viagem feita coletivamente no que ela porta de transformações e questionamentos: um pequeno épico da área de saúde coletiva que informa sobre as consequências dos eventos em relação às necessidades e aos desejos humanos ${ }^{23,26}$. Ao assinalar os grandes marcos do desenvolvimento da Revista, busquei ressaltar o contexto dos avanços, o processo de legitimação $0^{25}$ e os problemas que o aumento exponencial da demanda acarreta. Comento apenas o último aspecto, objeto de discussão em várias áreas e em muitos países $^{27,28}$. Olhando para o caso da C\&SC, faço coro com Rego ${ }^{29}$ quando diz que se, por um lado, o alto índice de rejeição de artigos demonstra a seriedade e o rigor dos pareceres e da política editorial adotada, por outro, ele pode ser entendido como indicativo da dificuldade da revista em captar artigos de qualidade, dada a fragilidade de grande parte da produção da área que se apresenta na porta de submissão dos originais. Esse é um problema intrinsecamente vinculado ao produtivismo acadêmico, tão pernicioso à ciência nacional e mundial. Vários autores têm se manifestado sobre o tema, realçando que seu centro indutor são as instituições de fomento, embora suas raízes sejam internacionais. Machado e Bianchetti ${ }^{30}$ ressaltam que a evolução do capitalismo calcado na ciência e na tecnologia empurra e reproduz essa situação perniciosa para todos os ramos do conhecimento. E Patrus et al. ${ }^{31}$ colocam os atores na roda da conversa, ao ressaltarem a alienação da comunidade científica, quando esta se mostra incapaz de enfrentar o problema que também depende dela.

A visão de futuro da Revista continua atrelada ao seu aprimoramento, à ética da divulgação cientifica e aos avanços da internacionalização. Seus parâmetros, além das normas acadêmicas convencionais, se vinculam às transformações editoriais exigidas pela ciência aberta, de um lado; e à popularização da ciência, de outro. Esses são os focos de investimento do presente, seguindo para o futuro ${ }^{32}$.

Ficou fora desta narrativa a discussão sobre o conteúdo da produção acadêmica que justifica a 
existência da C\&SC, porque este artigo faz parte da Edição Comemorativa em que renomados autores da área de Saúde Coletiva fazem uma imersão no que foi divulgado nesses 25 anos. O leitor terá na leitura da revista como um todo na busca de entender os caminhos percorridos, críticas sobre as falhas, ausências e vazios e, junto com os autores, são nossos convidados para prospectar o futuro.

E termino com uma reflexão amadurecida junto com Romeu Gomes ${ }^{21}$, seguidores que somos do pensamento de Bourdieu ${ }^{33}$. A Ciência \& Saúde Coletiva é um espaço estruturado do habitus da Saúde Coletiva e ao mesmo tempo é criadora de seu próprio habitus. Ela assume um papel importante na ordem estabelecida pelo campo da saúde e contribui para sua legitimidade e transformação: consagra, serve de filtro seletivo, atesta valor ao que é produzido, assegura a propriedade intelectual, legitima novos temas e define o que é publicável ${ }^{21}$. Esse conjunto de ações tem a marca subjetiva e intersubjetiva de todo o seu corpo constitutivo: editores-chefes, comissão de política editorial, editores associados, conselheiros editoriais, autores, avaliadores ad hoc, equipe executiva, indexadores e leitores. 


\section{Referências}

1. Bruner J. Atos de significação. São Paulo: Artmed; 2002.

2. Gadamer H. Verdade e método. Petrópolis: Editora Vozes; 1999.

3. Evans-Pritchard EE. Ensayos de Antropología Social. Madrid: Siglo XXI; 1990.

4. Lévi-Strauss C. O homem nu. Mitológicas IV. São Paulo: Cosac Naify; 2011.

5. Lima NT, Santana JP, Paiva CHA. Os 35 anos da história da Abrasco em um livro. Rio de Janeiro: Editora Fiocruz; 2015.

6. Minayo MCS. Pós-Graduação em Saúde Coletiva: Um Projeto em Construção. Cien Saude Colet 1997; 2(12):53-71.

7. Nunes ED, Costa OS. Os Cursos de Saúde Coletiva no Brasil: Mestrado e Doutorado: Um Estudo sobre as Disciplinas Básicas. Cien Saude Colet 1997; 2(12):72-90.

8. Goldenberg PG, Schenkman S. Os Egressos de PósGraduação em Saúde Coletiva: Construindo um Perfil. Cien Saude Colet 1997; 2(1-2):91-107.

9. Tanaka ACA. Perfil da Demanda aos Cursos de PósGraduação de 1996, na área de Saúde Coletiva. Cien Saude Colet 1997; 2(1-2):108-116.

10. Luz MT. A Produção Científica em Saúde Coletiva (1994-1995). Cien Saude Colet 1997; 2(1-2):117-141.

11. Viacava F, Ramos CL. Difusão da Produção Científica dos Cursos de Pós-Graduação em Saúde Coletiva. Cien Saude Colet 1997; 2(1-2):142-153.

12. Minayo MCS, Costa OS. Rumos e Desafios: Encerrando um Processo de Avaliação da Pós-Graduação Stricto Sensu em Saúde Coletiva (1994-1997). Cien Saude Colet 1998; 3(1):83-93.

13. Minayo MCS, Gomes R, Silva AAM. 25 anos de ciência para construção do SUS. Cien Saude Colet 2020; 25(3):780-780.

14. Horta BL, Bonfim LT, Moraes CL. Documento da área de Saúde Coletiva. Brasília: CAPES; 2019.

15. Guimaraes R. Política de Ciência, Tecnologia e Inovação em Saúde. Cien Saude Colet 2019; 24(3):881-886.

16. Mansell R, When U. Knowledge societies: information technology for sustainable development. Oxford: Oxford University Press; 2020.

17. Chetty LR. The role of science and technology in the developing world in the 21th century. Institute for ethics and emergein thecnologies 2012. [acessado 2020 Jun 5]. Disponível em: https://ieet.org/index.php/ IEET2/more/chetty20121003\#: :text=Science $\% 20$ and $\% 20$ technolo

18. Bourdieu P. Esboço de uma teoria da prática. Oieras: Celta; 2002.

19. Elias N. A sociedade dos indivíduos. Rio de Janeiro: Editora Zahar; 1994.
20. Popper K. A lógica da pesquisa científica. São Paulo: Editora Cultrix; 2003.

21. Minayo MCS, Gomes R. Ciência \& Saúde Coletiva no contexto nacional e internacional da divulgação científica. Cien Saude Colet 2015; 20(7):2013-2022.

22. Beigel F. Publishing from the periphery: Structural heterogeneity and segmented circuits. The evaluation of scientific publications for tenure in Argentina's CONICET. Current Sociology 2014; 62(5):743-765.

23. Labov W. Some Further Steps in Narrative Analysis. Journal of Narrative and Life History 1997; 7(14):395415.

24. Durkheim E. As regras do método sociológico. São Paulo: Martins Fontes; 1995.

25. Weber M. Economía y sociedad: esbozo de sociología comprensiva. Madrid: Fondo de Cultura Económica; 1994.

26. Paiva VLMO. A pesquisa Narrativa. Uma introdução. Revista Brasileira de Linguistica Aplicada 2008; 8(Supl. 1):1-5.

27. Rocha RM. As razões do produtivismo: fricções intelectuais e capitalismo ficcional. Galáxia 2018; 39(4):136-149.

28. Lorenz-Meyer D. The Academic Productivist Regime: Affective Dynamics in the Moral-Political Economy of Publishing. Science as Culture 2018; 27(2):151-174.

29. Rego TC. Produtivismo, pesquisa e comunicação científica: entre o veneno e o remédio. Educ. Pesqui 2014; 40(2):325-346.

30. Machado AMN, Bianchetti L. (Des)fetichização do produtivismo acadêmico: desafios para o trabalhador-pesquisador. RAE-Revista de Administração de Empresas 2011; 51(3):1-12.

31. Patrus R, Dantas DC, Shigaki HB. O produtivismo acadêmico e seus impactos na pós-graduação stricto sensu: uma ameaça à solidariedade entre pares? $\mathrm{Cad}$ EBAPE 2015; 13(1):1-18.

32. Packer AL, Santos S. Ciência Aberta e o novo modus operandi de comunicar pesquisa. Boletim Informativo da Sociedade Brasileira de Ciência do Solo 2019; 45(1):7-24.

33. Bourdieu P. Os usos sociais da ciência: por uma sociologia clínica do campo científico. São Paulo: UNESP; 2004.

Artigo apresentado em 25/06/2020

Aprovado em 25/06/2020

Versão final apresentada em 27/06/2020 